\title{
Finding the Sweet Spot: Network Structures and Processes for Increased Knowledge Mobilization
}

\author{
Patricia Briscoe \\ Niagara University \\ Katina Pollock \\ Western University \\ Carol Campbell \\ University of Toronto \\ Shasta Carr-Harris \\ University of Toronto
}

\begin{abstract}
The use of networks in public education is one of many knowledge mobilization (KMb) strategies utilized to promote evidence-based research into practice. However, challenges exist in the ability to mobilize knowledge through networks. The purpose of this paper is to explore how networks work. Data were collected from virtual discussions for an interim report for a province-wide government initiative. A secondary analysis of the data was performed. The findings present network structures and processes that partners were engaged in when building a network within education. The implications of this study show that building a network for successful outcomes is complex and metaphorically similar to finding the "sweet spot." It is challenging, but networks that used strategies to align structures and processes proved to achieve more success in mobilizing research to practice.
\end{abstract}

Keywords: networking, knowledge mobilization (KMb), network structure, network processes, network alignment, education.

Patricia Briscoe is an Assistant Professor, College of Education, Niagara University and former Knowledge Mobilization Network Manager of the KNAER.

E-mail: pbriscoe@niagara.edu

Katina Pollock is an Associate Professor of Educational Leadership, Western University and is the Director of the KNAER Secretariat

E-mail: kpolloc7@uwo.ca

Carol Campbell is an Associate Professor at OISE, University of Toronto, and is the Director of the KNAER

Secretariat

E-mail: carol.campbell@utoronto.ca

Shasta Carr-Harris is a PhD student at OISE, University of Toronto, and is the KNAER Knowledge Mobilization Manager.

E-mail: shasta.carr.harris@utoronto.ca 


\section{Introduction}

In the past few decades, discussions about how to improve public services have included attention to evidence-informed decision-making, policies, and practice. Despite growing awareness of the need for research to better inform the education sector, the ways in which academic research impacts education are still far from explicit (Cooper, 2012). Encouragement for stakeholders to generate discussions on strategies for connecting evidence-based research and practice to education is gaining momentum, and therefore, the notion of knowledge mobilization $(\mathrm{KMb})$ is becoming a guiding principle (Bienzle et al., 2007). Although KMb has many interpretations, it can be broadly defined as intentional effort to increase the use of research evidence (data collected through systematic and established formal processes of inquiry from empirical work) in policy and practice in the education sector among and between individual, organizational, and system levels (Nutley, Walter, \& Davies, 2007; Qi \& Levin, 2011). KMb occurs through intricate social processes involving interaction among groups or contexts to improve the broader education system (Cooper, 2012). This suggests that a powerful avenue to change practice is through networks, as networks have the potential to create ongoing social contact (Gilchrist, 1995, 2000; Watson, Townsley, \& Abbott, 2002).

The use of networks in public education is one of many $\mathrm{KMb}$ strategies utilized to promote turning evidence-based research into practice. There is ample evidence to suggest that school-to-school networks and partnerships are likely to be powerful ways to increase the means for education improvements (Castells, 2001; Church et al., 2002). School partnerships involving external networks with research-practitioner relationships are increasingly being seen as a means of facilitating $\mathrm{KMb}$ for increasing research use in practice (Ainscow, Muiji, \& West, 2006; Chapman, 2008; Chapman \& Fullan, 2007; Earl \& Katz, 2007; Hargreaves, 2003; Organisation for Economic Co-operation and Development [OECD], 2000).

Currently, there is extensive research pointing to the importance of building network connections (Finnigan \& Daly, 2014; Nutley et al., 2007). However, the idea of networks and networking can be adopted without an understanding of the complexity and challenges of effective $\mathrm{KMb}$ through external partnership networks. Continuously exploring means for increased $\mathrm{KMb}$ is a dedicated endeavour for all educational partners (Ontario Education Research Panel, [OERP], 2006). Nevertheless, evidence regarding how networks are established and operate in education systems to increase KMb is sparse (Best \& Holmes, 2010; Provan, Fish, \& Sydow, 2007). A clearer understanding is needed about what to emphasize in order to foster successful and productive networks in education. The purpose of this paper is to explore how structures and processes of networks are built within education for increased KMb of research-based evidence to practice. The paper presents a secondary analysis of findings from a qualitative study. This article is framed around concepts of network structure and processes with a focus on an alignment of the two. From these findings, leadership teams, researchers, project coordinators, intermediaries, and the like can gain a deeper understanding and know-how to mobilize research knowledge across their networks with the goal of improving education.

\section{Networks}

Networks are complex and contested. For this article, we specifically focus on social networks for the purpose of building partnerships. Although social networks are recognized as a powerful 
medium for sharing knowledge and effecting change (Daly, 2010; Degenne \& Forsé, 1999; Kilduff \&Tsai, 2003), they are also difficult to build and maintain (Gowdy, 2006).

Networks can be formal, informal, or a combination of both (Ávila de Lima, 2010; Bate \& Robert, 2002; Brass, Galaskiewicz, Greve, \& Tsai, 2004), and they can exist in the private and public sector, industry, government, and not-for-profit organizations. Networks in education are described as "groups or systems of interconnected people and organizations (including schools) whose aims and purposes include the improvement of learning and aspects of well-being known to affect learning” (Hadfield, Jopling, Noden, O’Leary, \& Stott, 2006, p. 5). Networks can occur within and across different levels of a sector (Borgatti \& Foster, 2003). Involvement in some networks can be time-consuming or with ad hoc groups; others require less involvement. Participation may be face-to-face in real time or virtual by asynchronous or synchronous means.

\section{Network Purpose}

Network purposes can vary drastically. Many educational networks exist at a macro level where the overall purpose is improving student and school learning or achievement. However, other purposes may require networks at a meso level (e.g., investigating how various norms of workplace behavior vary across professions) or micro level (e.g., an examination of "the self") (Borgatti \& Foster, 2003). In this article, we consider a specific kind of network: networks for $\mathrm{KMb}$.

\section{Education Networks for the Purpose of Knowledge Mobilization}

The networks explored in this article focuse on utilizing $\mathrm{KMb}$ strategies to connect bodies of evidence-based research to education practice. They are engaged in specific KMb efforts to:

- push and pull knowledge,

- build capacity among professionals,

- create $\mathrm{KMb}$ professional development tools based on research-based evidence, and

- act as knowledge brokers.

These networks are complex. We wanted to know how these networks were structured and what network processes were utilized.

\section{Alignment of Structures and Processes in Networks to Mobilize Evidence-based Education Research}

Networks that mobilize evidence-based educational research into practice could be considered learning partnerships. According to Earl and Katz (2005), networks are complex interactions between structures that create and support the network and activities that are carried out. The ways in which the network stakeholders organize and interact are not always predictable or similar. Our conceptual framework consists of three concepts:

- network structures,

- networking processes, and

- alignment.

Brock Education Journal, 25 (1), Fall 2015 
Specifically, we consider the manner in which network structures and their processes are aligned. Our overarching goal is to use this lens of aligning structures and processes to build or extend $\mathrm{KMb}$ networks in order to increase research use in the classroom and improve student learning.

\section{Structure and Process}

Networking draws on a complex mixture of structures and processes to bring people together in partnerships to generate and transfer new or existing knowledge. We frame this paper with the following definitions of network structure, processes, and alignment.

Network structure. Network structure is defined as coordination in the organizational design of a network to carry out interactions between partners. An organizational design creates a defined, manageable, and thus predictable flow of inputs and outputs through a network for performing strategies that achieve the desired result (Worren, 2012). Network structures also include supports that allow a network to function in an organized way. Supports can include formal and informal policies and practices such as formalized groups or roles, resources such as hired personnel and funding, or some infrastructure for communication such as a shared web platform.

Network processes. Network processes are purposeful and coordinated activities performed vertically and laterally within a network to interact with organizational partners. The intended outcome is to accomplish some goal(s). Typically two-way flow of processes is used in networks to disseminate and receive information. These processes focus on specific aspects for value creation and distribution such as activities for creating new products, providing services, interpreting research/data, and building relationships (Worren, 2012).

Alignment. Network structures and the processes they engage in can work independently. However, to achieve end goals, synchronization of both is necessary. This is known as alignment, which stems from the idea to "match," "align," or "fit" resources or common goals to intended outcomes (Andrews, 1971; Chandler, 1962; Venkatraman \& Camillus, 1984). Overall, alignment is "the degree to which the needs, demands, goals, objectives, and structure of one partner are consistent with the needs, demands, goals, objectives, and/or structure of other partners" (Nadler \& Tushman, 1980, p. 40). For example, networks can engage in a process to co-produce audience-appropriate resources and have appropriate communication structures to disseminate the products.

In the end, it is the ways in which networks align the structures they work within and the processes they enact that will determine their success (Worren, 2012). Gupta, Karimi, and Somers (1997) found that success is heightened when network structures and processes are aligned with focused strategies or goals; this ensures the organizations or partners are well positioned to work together to change practice and produce professional development tools or resources for goal attainment. The more network structures and processes are aligned with network partners, the fewer barriers and challenges are likely to exist. For example, when network partners have completed a needs assessment and established a common goal (or goals), processes of creating and disseminating professional development tools to achieve the goal can be more effective. A challenge in achieving alignment is identifying specific sources of interdependencies and interrelationships in structure and processes to improve alignment. Such identification is complex because of the interacting social nature of processes, which includes key components such as relationships and trust (Siggelkow, 2001). Orchestrating a network that simultaneously addresses 
the interdependency and interrelationships of structures and processes for creating synchronicity for effective $\mathrm{KMb}$ is a challenging endeavour.

\section{Methodology}

This article is based on a province-wide government initiative. The initiative was a unique, four-year KMb effort called The Knowledge Network for Applied Education Research (KNAER). The KNAER was a collaborative partnership between the Ontario Ministry of Education, the University of Toronto, and the University of Western Ontario. The goal was to support evidence-based, research-informed decisions connected to Ontario's provincial education goals. The KNAER funded 44 projects that focused on mobilizing research-based evidence throughout the province. The main findings and analyses presented in this study were generated from data collected for an interim government report investigating how best to support KMb networks within the KNAER projects. For the initial analysis and report writing, each primary investigator of a KNAER project was sent an invitation via email to participate in a virtual discussion about networking. Eight virtual sessions were scheduled within a three-week period. To accommodate as many participants as possible, options for face-to-face interviews, phone interviews, and written submissions were also included. In total, 21 people participated from 19 of the 44 projects, of which five people contributed to more than one session. In the end, the data were collected through eight web conferences using Blackboard interface, one face-to-face interview, one phone interview, and five written submissions. All sessions were recorded and transcribed for analysis. The data were collected between November 9 and December 3, 2012. Before the sessions, participants were provided with three main questions:

1. What networking strategies (e.g., relationship building, dissemination of knowledge products, network creation, and network expansion) are working well within your network?

2. Other than time and funding, what challenges are you experiencing with your networking?

3. How can we make connections to education organizations (e.g., schools, boards, professional associations, universities, and government) to access, share, understand, and use research-based knowledge?

From the initial data analysis of the challenges the participants encountered when supporting $\mathrm{KMb}$ networks and the best strategies they employed to overcome some of these challenges, we realized that $\mathrm{KMb}$ networks were complex and not only required linear cause and effect solutions, but also an exploration of the network composition. For this reason, the secondary analysis also included a document analysis of $\mathrm{KMb}$ plans, interim reports, and final project reports.

\section{Data Analysis}

It became clear during the initial analysis that capturing themes encountered in $\mathrm{KMb}$ networking and strategies employed to build networks was helpful, but only in terms of recognizing the challenges and strategies. Upon completion of our final report to the Ontario government, two years later, our continued learning led us to re-consider $\mathrm{KMb}$ networks as complex structures (Pollock, Campbell, \& Briscoe, 2015). This enabled us to re-conceptualize the data from the interim data collection through notions of network structures, the processes they engaged in, and 
the alignment of these structures and processes (Baker \& Jones, 2008). The secondary analysis involved re-analyzing the data from the interim report, including the simultaneous re-coding of the raw data and the construction of categories and subcategories connected to network structures, processes, and the alignment of the two. Coding was assigned on two levels: identifying information about the data by designation of key words surrounding network structure or processes, and interpretive constructs related to the analysis (Merriam, 1998). Our findings are presented based on the two areas of our conceptual framework: (a) network structures for success and challenges and (b) processes KMb networks engaged in and challenges.

The document analysis phase included an analysis of the $44 \mathrm{KMb}$ plans submitted at the commencement of the initiative, the 141 interim reports submitted during the initiative, and the 43 final project reports submitted at the end of the KNAER funding. Detailed KMb plans were submitted and provided general information such as:

- an overview of the project,

- budget request,

- project lead,

- partnership information and qualifications, and

- relevant experience and expertise of those involved in the project.

Additionally, the KMb plans outlined a project work plan or action plan, which included a statement of objectives, focus/alignment with Ministry priorities, partnerships, and any connection to previous research.

The interim reports asked project principal investigators to report on the following:

- accomplishments,

- next steps,

- challenges, and

- success stories.

The final reports requested:

- information about projects,

- an outline of the action plan that included activity/output,

- $\mathrm{KMb}$ products,

- KMb events,

- KMb networks,

- additional impact measures,

- KMb efforts,

- challenges,

- success stories/accomplishments, and

- recommendations. 


\section{Findings}

Several themes emerged about structures and processes for building new networks or expanding existing networks for $\mathrm{KMb}$. In this study, network structures are framed as organizational designs to carry out interactions between partners within networks.

\section{Network Structures for Success}

Our analysis indicated the following components of successful networks:

- similar goals and objectives to current government priorities,

- inclusion of key people and organizations,

- formal roles and responsibilities, and

- organized methods of communication.

Network goals/objectives similar to current government priorities. All KNAER projects were required to indicate in their proposal their goal alignment with that of the provincial government. However, aligning goals within a written proposal and then establishing these in practice was not entirely the same. KMb networks that had explicitly similar goals and objectives to the current government priorities had a clear advantage over those networks that had goals that were more generally connected. The goals set by Terry's (pseudonyms are used in this study) network are aligned with one of the four Ministry priority areas. Terry stated: "We have heard loud and clear that our network goals have to align across the different branches: their messaging and their focus." KMb networks that did not clearly articulate to partners that their goals were central to Ministry priorities appeared to encounter more difficulty in carrying their KMb plans to fruition. As indicated by Paula, "some boards have found that it's not a priority or people don't understand what information is being disseminated." Andy reiterates a similar message: "School boards tell me indirectly that's a really good idea but 'we're not going there right now.' The decision makers have decided they're not going to, or they don't want to become involved. It's just not the right time." We know that successful networks are those that have clearly defined goals. However, for some KNAER project networks that had come together around agreed upon goals, this alone was not enough to gain momentum for making a meaningful impact. Participants' feedback demonstrates how, for $\mathrm{KMb}$ networks, the goals or objectives had to align with those of government priorities and be clearly communicated to partners. Otherwise, networks found they had limited influence.

Key people and organizations as members. KNAER networks were encouraged to create partnerships with different stakeholders. Within KNAER's 44 projects, on average, each project had four partners; in total, there were approximately 150 partners, including 60 partnerships with a community organization, 46 with school boards, 22 with universities, 10 with health organizations, and 8 with colleges. However, it was not necessarily the number or types of existed partnerships that created success, but whether the organizations or individuals chosen as partners possessed access to end users, or participated in top-level decision making at the district or provincial level. All members of the 21 projects represented in this study mentioned involving strategic people and organizations as network members. As Sandra commented: "It's not just about diversity [of people within a network], but a diverse network made up of key strategic people." Kimberley indicates what kind of strategic person she thought would help support her 
network: "I was looking for people who weren't just involved, but those who are very community oriented and have done a lot of work for the community. It was a selective process..." In addition to including strategic individuals, many $\mathrm{KMb}$ networks strategically developed partnerships with key organizations that could support their goals. For example, Robbie explained: "We had the Canadian Mental Health Association, different parents' associations, and the health units....We tried to develop a group of people that are actively passionate about this cause to get involved and then we can disseminate information further." While some KMb networks were creating new working relationships with key organizations, others were relying on nurturing existing relations. Doug commented:

We established relationships with the teachers' union eight years ago. It was valuable because it gave us direct access to teachers that we couldn't get any other way. We didn't have to go through school boards for access. We went through the teachers' union summer institute list, so we had email and direct access to teachers across the province.

It is clear that multiple partnerships were an asset to successful KMb networks. However, when access to key people was limited, challenges occurred. Haley stated: "There are people who are high up on the school board, and they haven't attended our events, and so a challenge for us is to access these people." Having key organizations and people involved meant that KMb networks had opportunities for increased access to possible end users of any materials created, and increased access to additional communication and advertising outlets, to name but a few advantages.

Formal roles within networks. Many projects indicated that formal leadership roles were necessary. Some of these positions were held by individuals while others were a collection of individuals, such as steering committees. Andrea explained that her network had "five coordinators work within each of their three different school board partners." Noah described how his network utilized steering committees:

Prior to building our network, we formed a steering committee to help decide on goals, communication. We arranged to have meetings with the superintendents to discuss what the projects were about and then discuss setting up steering committees. The committee would be comprised of people that the school board and superintendents thought would be good representatives on behalf of the teachers.

As Noah stated, formal roles within the networks were established to help achieve the goals and objectives. Moreover, because KMb networks were complex with multiple partners, formal roles were assigned or responsibilities designated to established better organization.

Formal communication structure(s). Because of the level of complexity, KNAER networks that appeared to have some impact included specific, intentional, and often formalized ways for participants to communicate about network goals, and to disseminate, share, and co-produce knowledge. For example, Terri's network produced a digital professional learning paper that was publicly available to all those involved in the network. The content of the paper included the network goals and suggestions that allowed teachers to see how this might look within their classrooms.

Not all networks had considered how they would communicate their decisions and actions. Challenges occurred when networks and their potential partners did not have clear structures in 
place for an easy flow of communication. As Andy commented: "Clear communication structures are crucial because they affect awareness and visibility of your network."

\section{KMb Network Processes}

The participants in this study indicated when network structures were in place, they then began to engage in particular kinds of processes. Network processes are framed as purposefully coordinated activities performed within a network to interact with network partners in order to improve KMb. Our analysis indicated that many participants were describing processes or actions needed for $\mathrm{KMb}$ networks to achieve some success. These processes included: creating opportunities to collaborate and co-create $\mathrm{KMb}$ products, motivating and incentivizing, and strategic planning. Furthermore, it became evident that the processes described did not work independently of each other, but rather they occurred interdependently.

Creating opportunities to collaborate and co-create KMb products. One of the KNAER's goals was to facilitate the development and dissemination of advanced knowledge through the application of applied education research to influence educational practices. It became clear that the networks that came together and were productive were those that intentionally operationalized their goals. These networks reported moving beyond notions of being a think tank or advisory group and provided opportunities for collaboration and co-creation. Approaches to outreach included different ways of collaborating and co-creating, such as engaging in communities of practice, developing and delivering workshops, and participating in online forums. For example, Sara commented: "We're running an Adobe Connect session after school for teachers to gain access to the knowledge. That way it's things they can take back to their classroom." Andy added: "We conducted six virtual sessions and created products from what other people have suggested." The networks established the mediums of collaboration as a way to share educational research with their partners. However, what was demonstrated by the more successful networks was that collaboration was a way of gaining information from participants to co-create products and generate ideas that were based on their needs rather than on predetermined plans. As Doug reiterated:

From the start we decided that we wanted to engage in a collaborative process: how can we work together to address both the school board's needs and the way they do things while also addressing the mandate of our grant?

He further explained: "During our two focus groups, we identified main themes that the practitioners wanted to address regarding mental health themes. We pinpointed a product that matched those needs very closely." In this case, there was a concerted effort to meet educators' needs.

It is important to note, however, that building collaboration is more than listening to practitioners' needs and providing a product; an effort must also be made to provide partners with a sense of ownership and include them in the decision-making process. As Andrea mentioned: "It's when people are actually engaged in the thinking and part of the process that we get something that goes beyond fairly superficial utilization." Network actions that involved collaborating with all partners led to a sense of co-ownership whatever was co-created. Projects that provided opportunities for partners to be engaged in processes saw much more KMb success 
within their network. Some networks struggled with creating opportunities for ownership and turned to additional ways to motivate and incentivize participation.

Motivating and incentivizing. To increase participation both within the network and, where appropriate, with end users, participants mentioned methods of motivating and incentivizing. As Sherri stated: "Unless people feel that there's a reason for them to connect with you, they might not do it. Therefore, it's really important to make the case for why it is helpful for them to connect." One way to "make the case" is to provide network partners or end users with $\mathrm{KMb}$ products that were written in audience-appropriate language and clearly explain why a product might be useful for them. Fran commented: "With our project, the most difficult part was getting educators to look at research. So we offered the information in a language that was friendly and useable for them." Describing research and findings in a language that appealed to practitioners was challenging for some project leaders who were unfamiliar with writing for a particular audience. Sherri explained that her network created a process for translating academic research into practical language for practitioners as a way to motivate researchers to engage and contribute their research:

To make it more appealing for researchers to submit their research and participate in our network, we had people write the summary for the researcher because the researcher might not want to spend a lot of time on that. We had a team with the skills necessary to do the work and that made it much easier for the researchers - they were more willing to partner with us.

Creating processes to produce audience-appropriate $\mathrm{KMb}$ products was a motivating factor for network partners to become connected to the network initiative of mobilizing research-to-practice knowledge.

In some cases, researchers were motivated to engage in KNAER projects because they could see how their input and ideas were being applied. For example, Tina commented:

There was an incredible willingness established when people see the quality of learning from participants and the quality of the records of practice developed through the project. We consistently and sincerely expressed our appreciation to the teachers and the students involved and to highlight their incredible wisdom and learning when sharing the artifacts with others. We honestly feel honoured to work with and learn from them, and I think that continually reiterating this to them and others has contributed to the willingness of others to engage in the learning as well.

When partners were involved, appreciated, and given credit for their role in KNAER projects, motivation increased. Doug stated that a sense of ownership also increases motivation and take-up: "It's very important that teachers can look at the knowledge products and say 'Oh my board was involved in this'." Noah explained that teachers need voices, "a chance to say: 'You know what, that's great in terms of research, but here are some of the things that I see are problematic and I face on a daily basis,' then giving them a venue to share". Other networks experienced challenges in terms of wanting to be more involved, but either did not have the time to get to know their partners, or lacked knowledge of presenting their research in a way useful for practitioners.

Another challenge for many networks was not motivating network partners, but sustaining the motivation momentum and finding time to come together and work collaboratively. For

Brock Education Journal, 25 (1), Fall 2015 
example, Cindy commented: "Once we establish relationships, coming up with the time to meet and collaborate that are mutually exclusive for people both working within our project and working in the classroom or on the boards, that's probably the biggest challenge." Some networks utilized incentives to engage practitioners in difficult conceptual work. Incentivization included release time, coaching, mentoring, and access to classroom resources. Incentivizing was not just targeted to end users and practitioners, but also to project leads who were academic researchers. Universities and school boards were encouraged to participate in the KNAER initiative through targeted funding to support $\mathrm{KMb}$. Financial support enabled the purchase of equipment and development of activities and products. Project leaders indicated that funding contributing to opportunities to write and publish was incentivizing. Cody explained:

We have five papers for presentation in 2013 annual research conference and we received budget pre-approval to cover the travel expense for two presenters to the conference... because of this, we have had broad dissemination, uptake, and implementation of the workshop materials across numerous networks, organizations, and ministries.

Cody's words demonstrate that project leads were incentivized by the possibilities and opportunities surrounding the publication of their network's work in academia and beyond.

Strategic planning. The KNAER networks that appeared most successful engaged in a realistic, cohesive, strategic plan with actions to establish and engage network partners in order to enact their network's KMb plans, goals, and objectives. Many KNAER networks ran the risk of creating numerous end products and organizing various opportunities, but doing so in a way where participants viewed the outputs as unconnected or "one-off" events. Some networks strategically utilized products as part of an event that was then subsequently included in other ongoing learning opportunities. For example, Suzanne's network established an electronic structure for engaging a core group of principals with researchers. The interactions between researchers and principals provided opportunities for learning and improvement thereafter, such as online tutorial/training sessions with technical support for new principals. The interactive website is an ideal avenue for collaboration between educational researchers and practitioners.

It became clear that the networks that were most effective were able to coordinate the outputs and activities through a strategic plan to create greater synergy among their partners. Some networks strategically implemented a communication process as part of their strategic plan. Andrea noted:

The network processes are set up so that the learning from any of the projects actually is intentionally shared... Face to face sessions and then online communication afterwards where we took all the big ideas we were working with, did investigations, and came back together to pool what we were learning and to kind of challenge one another's thinking...

Effective networks require a continuous two-way flow of information with strategic underlying plans that involve evaluating received information and forming next steps. While it is necessary to be flexible when developing plans and changing them as issues arise, it is also important to keep the network's ultimate goal(s) in mind. As previously indicated, having key people or organizations involved in the network was an intentional strategy. However, successful networking takes more than key people; it takes strategic planning to offer the key people the right information and the right direction. 


\section{Discussion}

Our findings indicate that the various $\mathrm{KMb}$ networks developed in different ways; some were better at executing parts of networking more than others. Some networks were better at aligning their goals with those of the Ministry while others developed succinct strategic plans or were less coordinated. Even though KNAER purposefully developed project proposals to foster some degree of alignment, we wanted to know how the networks were structured and what network processes were utilized. What became clear to us was that some KMb networks were strong in various structural and procedural aspects of networking, but few were proficient in all of the categories listed in the findings section of this paper. For networks that did come close to demonstrating the structural and procedural aspects of $\mathrm{KMb}$ networking mentioned in our findings, a phenomenon of alignment appeared to occur to connect structural components and processes to fulfil network mandates. We highlight the interdependence of network structure and processes because there are many individuals, groups, and stakeholders that form structures that may initially be considered networks, but work more like advisory boards and think tanks that do little in terms of direct action with knowledge mobilization (McCleaster, 2010). A few well-meaning networks came together to brainstorm, engage in discussions, and share information, but experienced difficulty moving beyond this stage of network development. Other groups came together and concentrated mainly on action and the process of "doing something," but were unorganized, unfocused, inconsistent, and failed to reflect and ask some difficult questions such as "What are we doing here?" or "Is there a better way to do this?" When networks aligned their structural components with action, they appeared to have further geographical reach, more outputs, an increased number of partnerships, and possibly a greater impact in terms of mobilizing research-based evidence into practice. Specifically, alignment is more than just the existence of network structures and their processes; alignment refers to the ways in which network members come together to create a synergy that moves the network towards achieving its goals.

One successful example is the KMb network called Extending the Child and Youth Mental Health Information Network: Sharing Mental Health Information with Educators. The network was focused on bringing together several school boards who were interested in improving mental health literacy and learning together about research and practice (which also aligned with Ministry priorities). This network comprised multiple key partners, including "The Child and Youth Mental Health Information Network," "E-BEST", "The Ontario Centre of Excellence for Child and Youth Mental Health," and school districts in Ontario. The network included a formal leadership role-the project leader (who was also the $\mathrm{KMb}$ Officer at the school board) - who was responsible for forming a professional learning community (PLC) consisting of invited stakeholders and experts. Formal communication and decision making occurred with the network's Primary Investigator and the PLC meeting every six to eight weeks for two years. In terms of co-collaboration and co-creation, the network created brief summaries of systematic reviews, and distributed printed copies of these to PLC members for sharing. The network also hosted a panel of Ministry and community speakers at an annual conference and supported individual boards to develop plans for improving mental health literacy for educators. The network appeared to keep up momentum through motivational strategies, such as connecting educators through a PLC and developing interventions that helped educators understand, identify, and educate children and youth with mental health problems. Network incentives consisted of forming a place to continue the project's efforts for sharing their work with the Mental Health ASSIST Initiative through the Ministry of Education. Lastly, optimum performance occurred when the 
$\mathrm{KMb}$ plan was strategically designed so that all events and products were integrally connected to one another.

\section{Conclusion}

The networks in this study that achieved the most success in mobilizing knowledge in education were those networks that were strategic in aligning their network structures and processes. Factors that contributed to alignment have been identified as structures and KMb network processes, which showed high interdependence and synergy to each other. The identified structures include goals and objectives similar to current government priorities, inclusion of key people and organizations, formal roles and responsibilities, and organized methods of communication. The identified processes involved creating opportunities for collaboration and co-creation of $\mathrm{KMb}$ products, motivating and incentivizing, and planning strategically. The networks involved in this study proved in various ways that achieving all these factors is like finding the "sweet spot," a situation or place where a combination of factors results in a maximum response for the given effort. In sports such as tennis or baseball, the sweet spot is achieved when the ball is hit in the ideal place on the racket or bat and results in the most powerful strike, imparting the greatest amount of forward momentum to the ball. Metaphorically speaking, KNAER projects that were even slightly off to the "sweet spot" encountered challenges and resulted in less than the desired amount of success. The metaphor of the sweet spot is relevant to building a successful network; finding the sweet spot is what we feel the networks in this study were trying to accomplish through the alignment of structures and processes to achieve their goals for educational improvement. Finding the sweet spot is challenging, yet not impossible, as demonstrated by these networks. When working at their sweet spot peak, networks are transformative for the institutions and people involved. However, networks are complex and strategic planning for alignment of structures and processes is necessary to find the sweet spot. Based on the findings of this study, KNAER has a deeper understanding of the complexities of how networks work and can assist individual networks with developing capacity and addressing challenges to further the success of their efforts, helping them find their sweet spot. 


\section{References}

Ainscow, M., Muijs, D., \& Mel West, M. (2006). Collaboration as a strategy for improving schools in challenging circumstances. Improving Schools, 9(3), 192-202.

Andrews, K. R. (1971). The concept of corporate strategy. Homewood, IL: Irwin.

Ávila de Lima, J. (2010). Thinking more deeply about networks in education. Journal of Educational Change, 11, 1-21.

Baker, J. \& Jones, D. (2008). A theoretical framework for sustained strategic alignment and an agenda for research" (2008). All Sprouts Content. 8(2) 1-30. Retrieved from http://aisel.aisnet.org/sprouts_all/222

Bate, S.P. \& Robert, G. (2002). Knowledge management and communities of practice in the private sector: lessons for modernizing the NHS in England and Wales. Public Administration, 80, 643-63.

Best, A. \& Holmes, B. (2010). Systems thinking, knowledge and action: Towards better models and methods. The Policy Press, 6(2), 145-159.

Bienzle, H., Gelabert, E., Jütte, W., Kolyva, K., Meyer, N. \& Tilkin, G. (2007). The art of networking: European networks in education. Wien/Austria: die Berater.

Borgatti, S. P. \& Foster, P. C. (2003). The network paradigm in organizational research: A review and typology. Journal of Management, 29(6), 991-1013.

Brass, D. J., Galaskiewicz, J., Greve, H.R., \& Tsai, W. (2004). Taking stock of networks and organizations: A multilevel perspective. Academy of Management Journal, 47(6), 795-817.

Castells, M. (2001). The Internet galaxy: Reflections on the Internet, business and society. Oxford, UK: Oxford University Press.

Chandler, A. D. (1962). Strategy and structure: Chapters in the history of American enterprise.Cambridge, MA: The MIT Press.

Chapman, C. (2008). Towards a framework for school to school collaboration in challenging circumstances. Educational Research, 50, 403-421.

Chapman, C., \& Fullan, M. (2007). Collaboration and partnership for equitable improvement: Towards a networked learning system? School Leadership and Management, 27, 207-211.

Church, M., Bitel, M., Armstrong, K., Fernando, P., Gould, H., Joss, S., \& Vouhé, C. (2002). Participation, relationships and dynamic change: New thinking on evaluating the work of international networks. London, UK: University College.

Cooper, A. (2012). Knowledge mobilization intermediaries in education: A cross-case analysis of 44 Canadian organizations (Unpublished doctoral dissertation). Ontario Institute for Studies in Education, Toronto, ON.

Daly, A. J. (2010). Social network theory and education al change. Cambridge, MA: Harvard Education Press.

Degenne, A., \& Forsé, M. (1999). Introducing social networks. London: Sage.

Brock Education Journal, 25 (1), Fall 2015 
Earl, L. \& Katz, S. (2005). What makes a network a learning network? National College for School Leadership. Retrieved from http://www.curriculum.org/secretariat/files Jan30AboutLearningNetwork.pdf.

Earl, L., \& Katz, S. (2007). Leadership in networked learning communities: Defining the terrain. School Leadership and Management, 27, 239-258.

Finnigan, K. S., \& Daly, A. D. (2014). Using research evidence in education: From the school house door to capitol hill. London, UK: Springer.

Gilchrist, A. (1995). Community development and networking, London, UK: Community Development Foundation.

Gilchrist, A. (2000). The well-connected community: Networking to the "edge of chaos." Community Development Journal, 36(3), 264-75.

Gowdy, E. A. (2006). Knowledge transfer and health networks: Literature review, Southern Alberta Child and Youth Health Network in Canada. Calgary, AB.

Gupta, Y. P., Karimi, J., \& Somers, M. T. (1997). Alignment of a firm's competitive strategy and information technology management sophistication: The missing link. IEEE Transactions on Engineering Management, 44(4), 399-413.

Hadfield, M., Jopling, M., Noden, C., O'Leary, D., \& Stott, A. (2006). What does the existing knowledge base tell us about the impact of networking and collaboration? A review of network-based innovations in education in the UK. Nottingham, UK: National College for School Leadership.

Hargreaves, D. (2003). Working laterally: How innovative networks make an education epidemic. London, UK: Demos/NCSL.

Kilduff, M., \& Tsai, W. (2003). Social networks and organizations. London, UK: Sage.

Merriam, S. B. (1998). Qualitative research and case study applications in education. San Francisco: Jossey-Bass.

McCleaster, S. (2010). The advisory board connection. FOCUS: Journal for Respiratory Care \& Sleep Medicine, 36+. Retrieved from http://go.galegroup.com.proxy1.lib.uwo.ca/ps/i.do?id=GALE\%7CA226661196\&v=2.1\& $\mathrm{u}=$ lond95336\&it=r\&p=AONE\&sw=w \&asid=c6fa4b2b930732ad6f745a3f03f7362c

Nadler, D., \& Tushman, M. (1980). A diagnostic model for organizational behavior. Organizational Dynamics, 9(2), 35-51.

Nutley, S., Walter, I., \& Davies, H. T. O. (2007). Using evidence: How research can inform public services. Briston, UK: Policy Press

Ontario Education Research Panel (OERP). (2006). Knowledge mobilization: An OERP perspective. Retrieved from http://www.edu.gov.on.ca/eng/research/OERP_KM_En.pdf

Organisation for Economic Co-operation and Development (OECD). (2000). Knowledge management in the learning society. Paris, France: Author. 
Pollock, K., Campbell, C. \& Briscoe, P. (2015, June). The Knowledge Network for Applied Education Research: Networking lessons. In P. Adams \& C. Bruce, Chairs), Action Research networks in Canadian context. Symposium conducted at the Canadian Society for the Study of Education, Ottawa, ON.

Provan, K. G., Fish, A., \& Sydow, J. (2007). Interorganizational networks at the network level: A review of the empirical literature on whole networks. Journal of Management, 33, 479-516.

Qi, J., \& Levin, B. (2011). Research knowledge mobilization in education. Report for the IALEI Annual Meeting \& Conference, OISE, University of Toronto, June 13-15. Retrieved from http://www.oise.utoronto.ca/rspe/UserFiles/File/IALEI_2011_Synthesis_Report.pdf

Siggelkow, N. (2002). Misperceiving interactions among complements and substitutes: Organizational consequences. Management Science, 48, 7, 900-917.

Venkatraman, N., \& Camillus, J. C. (1984). Exploring the concept of "fit" in strategic management. Academy of Management Review, 9(3), 513-525.

Watson, D., Townsley, R., \& Abbott, D. (2002). Exploring multi-agency working in services to disabled children with complex healthcare needs and their families. Journal of Clinical Nursing, 11, 367-375.

Worren, N. (2012). Organisation design: Re-defining complex systems. Essex, England: Pearson Education Limited. 